\title{
Love-related changes in the brain: a resting-state functional magnetic resonance imaging study
}

\section{Hongwen Song ${ }^{1+}$, Zhiling Zou ${ }^{1 *+}$, Juan Kou ${ }^{1}$, Yang Liu ${ }^{1}$, Lizhuang Yang ${ }^{2}$, Anna Zilverstand ${ }^{3}$, Federico d'Oleire Uquillas ${ }^{3}$ and Xiaochu Zhang ${ }^{2,4,5}$ *}

${ }^{1}$ Faculty of Psychology, Southwest University, Chongqing, China

${ }^{2}$ CAS Key Laboratory of Brain Function \& Disease, School of Life Sciences, University of Science and Technology of China, Anhui, China

${ }^{3}$ Icahn School of Medicine at Mount Sinai, New York, NY, USA

${ }^{4}$ CAS Center of Medical Physics and Technology, University of Science and Technology of China, Anhui, China

${ }^{5}$ School of Humanities and Social Science, University of Science and Technology of China, Anhui, China

\section{Edited by:}

John J. Foxe, Albert Einstein College of Medicine, USA

\section{Reviewed by:}

Inga D. Neumann, University of Regensburg, Germany

Rosalyn J. Moran, Virginia Tech, USA

*Correspondence:

Xiaochu Zhang, CAS Key Laboratory of Brain Function \& Disease, School of Life Sciences, University of Science and Technology of China, Hefei, Anhui 230027, China e-mail: zxcustc@ustc.edu.cn: Zhiling Zou, Faculty of Psychology, Southwest University,

Chongqing 400715, China e-mail:zouzl@swu.edu.cn

${ }^{t}$ These authors have contributed equally to this work and shared first authorship.
Romantic love is a motivational state associated with a desire to enter or maintain a close relationship with a specific other person. Functional magnetic resonance imaging (fMRI) studies have found activation increases in brain regions involved in the processing of reward, motivation and emotion regulation, when romantic lovers view photographs of their partners. However, not much is known about whether romantic love affects the brain's functional architecture during rest. In the present study, resting state functional magnetic resonance imaging (rsfMRI) data was collected to compare the regional homogeneity (ReHo) and functional connectivity (FC) across an "in-love" group (LG, $N=34$, currently intensely in love), an "ended-love" group (ELG, $N=34$, ended romantic relationship recently), and a "single" group (SG, $N=32$, never fallen in love). Results show that: (1) ReHo of the left dorsal anterior cingulate cortex (dACC) was significantly increased in the LG (in comparison to the ELG and the SG); (2) ReHo of the left dACC was positively correlated with length of time in love in the $L G$, and negatively correlated with the lovelorn duration since breakup in the ELG; (3) FC within the reward, motivation, and emotion regulation network (dACC, insula, caudate, amygdala, and nucleus accumbens) as well as FC in the social cognition network [temporo-parietal junction (TPJ), posterior cingulate cortex (PCC), medial prefrontal cortex (MPFC), inferior parietal, precuneus, and temporal lobe] was significantly increased in the LG (in comparison to the ELG and SG); (4) in most regions within both networks FC was positively correlated with the duration of love in the LG but negatively correlated with the lovelorn duration of time since breakup in the ELG. This study provides first empirical evidence of love-related alterations in brain functional architecture. Furthermore, the results shed light on the underlying neural mechanisms of romantic love, and demonstrate the possibility of applying a resting-state $\mathrm{fMRI}$ approach for investigating romantic love.

Keywords: romantic love, resting state fMRI (rsfMRI), regional homogeneity (ReHo), functional connectivity (FC), dorsal anterior cingulate cortex (dACC), nucleus accumbens, temporo-parietal junction (TPJ), posterior cingulate cortex (PCC)

\section{INTRODUCTION}

Romantic love, a very old topic, has been recorded in the poetry, songs, stories, myths, and legends of human civilization for 1000s of years (Jankowiak and Fischer, 1992; Baumeister et al., 1993). It has been regarded as the inspiration for some of the most extraordinary achievements of mankind (Bartels and Zeki, 2000), and plays an important role in human survival, reproduction, development, and evolution (Fisher, 1998).

Within the last century, romantic love has also become a topic of interest for scientists. Psychologists, for example, define romantic love as a motivational state associated with a desire to enter or maintain a close relationship with a specific other person (Aron and Aron, 1991; Cacioppo et al., 2012; Diamond and Dickenson, 2012). Love has also been shown to play a role in mediating reward and goal-directed motivation (Cacioppo et al., 2012; Diamond and
Dickenson, 2012). It can alter cognition and behavior, such as promoting intensely focused attention on the preferred individual, accompanied by euphoria, craving, obsession, compulsion, distortion of reality, emotional dependence, personality changes, and risk-taking (Peele and Brodsky, 1975; Clark and Mills, 1979). Romantic love is thus a complex sentiment, involving emotional, cognitive, and behavioral components (Sternberg, 1986; Hazan and Shaver, 1987).

In recent years, researchers have devoted increasing attention to the neurobiological substrates and neurological processes of romantic love. Bartels and Zeki (2000) published the first functional magnetic resonance imaging (fMRI) study investigating the brain of a person looking at a photograph of someone whom they love. Many other researchers have further studied the pattern of brain activity of those who are in love using similar tasks 
(Bartels and Zeki, 2000, 2004; Aron et al., 2005; Ortigue et al., 2007; Acevedo and Aron, 2009; Fisher et al., 2010; Xu et al., 2011). Reviews of these studies conclude that love is accompanied by significantly increased activation in brain regions such as the ventral tegmental area (VTA), medial insula, anterior cingulate cortex (ACC), hippocampus, nucleus accumbens (NAC), caudate nucleus, and hypothalamus. At the same time, deactivations can be found in the amygdala, prefrontal cortex (PFC), temporal poles, and temporo-parietal junction (TPJ; Zeki, 2007; de Boer et al., 2012; Diamond and Dickenson, 2012; Tarlaci, 2012). Cacioppo etal. (2012) have suggested that romantic love-related brain regions can be divided into subcortical and cortical brain networks where the former mediates reward, motivation, and emotion regulation, and the latter mainly supports social cognition, attention, memory, mental associations, and self-representation.

However, it remains unclear whether romantic love also affects the functional architecture of the brain. After Biswal et al. (1995) proposed that functional connectivity (FC) can be studied using resting state functional magnetic resonance imaging (rsfMRI), Raichle et al. (2001) proposed the use of rsfMRI for investigating the brain when no specific task is pursued. Compared to task-fMRI, rsfMRI is a tool for exploring the intrinsic functional architecture of the brain (Fox and Raichle, 2007; Van Den Heuvel and Hulshoff Pol, 2010; Chou et al., 2012; Lee et al., 2013). This approach helps avoid potential confounds and limitations encountered in task-based approaches (e.g., practice, ceiling or floor effects, or differential performance levels; Di Martino et al., 2008). RsfMRI thus provides promising opportunities for investigating the functional topology of the brain and has been widely used to study differences between populations, too (Fox and Raichle, 2007; Van Den Heuvel and Hulshoff Pol, 2010).

Most rsfMRI studies have adopted FC to examine the correlations and dynamics between brain networks. FC is defined as the correlation of spontaneous blood oxygen level-dependent (BOLD) signals between spatially remote regions (Aertsen et al., 1989; Friston et al., 1993). This measure describes the relationship between neuronal activation patterns of anatomically separated brain regions and networks (Van Den Heuvel and Hulshoff Pol, 2010). FC has been widely used to study clinical populations such as schizophrenia (Lynall et al., 2010), Parkinson's disease (Stoffers et al., 2008), autism spectrum disorder (Koshino et al., 2008), depression (Greicius et al., 2007), and substance abuse and dependence (Liu et al., 2010). However, FC provides little information about local features of spontaneous brain activity observed in individual regions.

In contrast, Regional Homogeneity (ReHo) is a local measurement of FC, defined as the temporary similarity between a given voxel and its neighbors (Zang et al., 2004). In this method, Kendall's coefficient of concordance (KCC) (Zang et al., 2004) is used to measure the correlation between the time series of a given voxel and its nearest neighbor voxels in a voxel-wise way. ReHo is a validated measure of brain functioning, measuring the synchronized oscillatory activity in the cerebral cortex that is essential for spatiotemporal coordination and integration of activity in anatomically distributed but functionally related neural elements (Van Rooy et al., 2005). Neuronal synchronization is also hypothesized to underlie the efficient organization of information processing in the brain (Buzsáki and Draguhn, 2004), facilitating the coordination and organization of information processing across several spatial and temporal ranges (Fox et al., 2005). In the past years, ReHo has been used to study a variety of populations including patients suffering from schizophrenia (Liu et al., 2006), Parkinson's disease (Wu et al., 2009), autism spectrum disorder (Paakki et al., 2010; Shukla et al., 2010), and depression (Yao et al., 2009).

Given that romantic love is a motivational state (Aron and Aron, 1991; Cacioppo et al., 2012; Diamond and Dickenson, 2012) and that there are many specific psychological and behavioral changes in romantic lovers (such as intensely focused attention on a preferred individual, obsession, and risk-taking; Peele and Brodsky, 1975; Clark and Mills, 1979) as well as facilitation of cognitive behavior (Bianchi-Demicheli et al., 2006; Ortigue et al., 2007), it is not strange to assume that being in love may affect the underlying functional architecture structure of the involved brain regions. In the present study, we computed both ReHo and FC from rsfMRI data to investigate these proposed alterations in functional brain architecture in romantic lovers.

\section{MATERIALS AND METHODS ETHICS STATEMENT}

This study was approved by the Ethics Committee of Southwest University. Written informed consent was obtained from all participants. All participants were informed that their participation was completely voluntary and that they may withdraw themselves at any time. All participants were over 18 years of age.

\section{PARTICIPANTS}

One hundred healthy college students were enrolled in the study. All participants were recruited from Southwest University (SWU, Chongqing, China) by flyers and Internet advertisement. They were interviewed at the beginning of the study procedure regarding previous romantic relationships and demographic characteristics. The participants were divided into three groups according to their previous romantic relationship: (1) the "in-love" group (LG; $N=34$ ), consisting of individuals currently intensely in love; (2) the "ended-love" group (ELG; $N=34$ ), consisting of individuals who had recently ended a close romantic relationship and were not currently in love; and (3) the "single" group (SG; $N=32$ ), consisting of individuals who had never fallen in love with anyone.

There were no significant differences in family income, personal monthly expenses, age, or years of education $(P>0.1)$ among either of the three groups (Table 1). The length of time in love of participants in the LG was between 4 and 18 months $(12.21 \pm 3.33)$. In the ELG, duration since the last romantic relationship breakup was between 2 and 17 months (10.41 \pm 2.97$)$, while the length of relationship before breaking-up was 439 months $(15.12 \pm 9.91)$. All participants were of heterosexual orientation.

\section{SELF-RATED QUESTIONNAIRES}

The Passionate Love Scale [PLS; Hatfield and Sprecher, 1986] was used to measure the status of passionate/romantic love in the LG. The PLS has been previously used in a sample of Chinese college 
Table 1 | Economic status, demographic, and romantic relationship status of participants.

\begin{tabular}{|c|c|c|c|c|c|c|c|c|}
\hline & \multicolumn{2}{|c|}{$\begin{array}{l}\text { LG (In-love group) } \\
\text { ( } N=34,16 \text { females) }\end{array}$} & \multicolumn{2}{|c|}{$\begin{array}{l}\text { SG (Single group) } \\
(N=32,14 \text { females) }\end{array}$} & \multicolumn{2}{|c|}{$\begin{array}{l}\text { ELG (Ended-love group) } \\
\qquad(N=34,15 \text { females) }\end{array}$} & \multirow[t]{2}{*}{$\boldsymbol{F}$} & \multirow[t]{2}{*}{$\boldsymbol{P}$} \\
\hline & Mean & SD & Mean & SD & Mean & SD & & \\
\hline Family income (RMB/months) & $4.10 \times 10^{3}$ & $7.04 \times 10^{2}$ & $4.04 \times 10^{3}$ & $6.22 \times 10^{2}$ & $4.04 \times 10^{3}$ & $6.82 \times 10^{2}$ & 0.1 & 0.91 \\
\hline Monthly expenses (months) & $7.35 \times 10^{2}$ & 78.32 & $7.41 \times 10^{2}$ & 86.7 & $7.40 \times 10^{2}$ & 63.72 & 0.05 & 0.95 \\
\hline Intensity of the love (PLS scores) & 104.21 & 10.58 & & & & & & \\
\hline Length of time in-love (months) & 12.21 & 3.33 & & & 12.11 & 9.91 & & \\
\hline $\begin{array}{l}\text { Lovelorn duration since breakup } \\
\text { of romantic relationship (months) }\end{array}$ & & & & & 10.41 & 2.97 & & \\
\hline
\end{tabular}

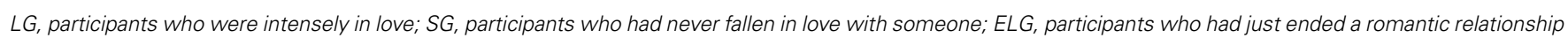
recently and were not currently in-love. PLS, Passionate Love Scale.

students (Xu et al., 2011; Yin et al., 2013). Average PLS score in the LG was 104.21, and SD was 10.58.

\section{SCANNING ACQUISITION AND IMAGE PREPROCESSING}

All imaging data were acquired using a 3T Siemens scanner (Siemens Medical, Erlangen, Germany) at the Brain Imaging Research Center of Southwest University. Resting state fMRI (rsfMRI) data were acquired using a T2*-weighted echo-planar imaging sequence [time repetition $(\mathrm{TR})=2000 \mathrm{~ms}$; time echo $(\mathrm{TE})=30 \mathrm{~ms}$; flip angle $=90^{\circ}$; field of view $(\mathrm{FOV})=220 \mathrm{~mm}$; Matrix $=64 \times 64,32$ slices; $3 \mathrm{~mm}$ slice thickness; voxel size $=3.4 \mathrm{~mm} \times 3.4 \mathrm{~mm} \times 3 \mathrm{~mm}$ ]. For each participant 242 contiguous EPI functional volumes were collected during one run of $8 \mathrm{~min}$ and $4 \mathrm{~s}$. Participants were instructed to lie in the scanner with eyes closed while thinking of nothing, and remaining still, relaxed, and awake throughout the scanning session (Hao et al., 2013). Additionally, high-resolution T1-weighted spin-echo images were collected $\left(\mathrm{TR} / \mathrm{TE}=1900 \mathrm{~ms} / 2.52 \mathrm{~ms}\right.$; flip angle $=9^{\circ}$; FOV $=256 \mathrm{~mm}$; Matrix $=256 \times 256 ; 1 \mathrm{~mm}$ slice thickness, 176 slices; voxel size $=1 \mathrm{~mm} \times 1 \mathrm{~mm} \times 1 \mathrm{~mm})$.

Imaging data were analyzed by Statistical Parametric Mapping software (SPM8; http://www.fil.ion.ucl.ac.uk/spm/ software/spm8/) using two processing toolkits [the Data Processing Assistant for Resting-State fMRI (DPARSF; Chao-Gan and Yu-Feng, 2009); and the resting-state fMRI data analysis Toolkit (REST; Song et al., 2010)]. Prior to processing, the first five functional volumes of each session were discarded to allow for scanner stabilization. Cerebrospinal fluid (CSF), and the white matter signals were removed by classifying them as nuisance variables so as to reduce the effect of head motion and non-neural BOLD fluctuations (Fox et al., 2005; Kelly et al., 2008). In the present study, we used white matter (white.nii), CSF (csf.nii), and the whole brain activity signal to perform a matrix multiplication to obtain the signal of the white matter and CSF (Chao-Gan and Yu-Feng, 2009). Data preprocessing using DPARSF consisted of: (1) slice-timing correction using Fourier interpolation to correct for differences in slice acquisition time; (2) 3D motion correction using least-squares alignment and a 3 translational and 3 rotational parameter linear transformation to correct for inter-scan head motion [movement threshold for translation $(x, y, z$ direction) was set at $2 \mathrm{~mm}$; rotational movement (roll, pitch, yaw) threshold was set at $2^{\circ}$; (3) spatial normalization to a standard template (Montreal Neurological Institute) with resampling to $3 \mathrm{~mm} \times 3 \mathrm{~mm} \times 3 \mathrm{~mm}$; (4) spatial smoothing using a 4-mm full-width-at-half-maximum (FWHM) Gaussian kernel; and (5) temporal band-pass filtering $(0.01-0.08 \mathrm{~Hz})$ to reduce low-frequency drift and high-frequency physiological noise.

\section{DEFINITION OF SEED REGIONS}

Based on previous results in task-fMRI studies of romantic love (Bartels and Zeki, 2000, 2004; Aron et al., 2005; Ortigue et al., 2007; Fisher et al., 2010; Xu et al., 2011), we selected ten regions of interest (ROIs) as seed regions for the FC analysis. Each ROI was a small $10 \mathrm{~mm}$ centered sphere (Table 2). To ensure that each ROI included only voxels of one brain region, these spheres were additionally masked with a corresponding region-mask to exclude neighboring anatomical structures.

\section{FUNCTIONAL CONNECTIVITY (FC) ANALYSIS}

The correlation maps for these seed regions were produced by computing correlation coefficients between the mean time series of each ROI and the time series of all other brain voxels for each participant. Correlation coefficients were converted to $z$-values using Fisher's $r$-to- $z$ transform to improve normality. In order to compare the FC across the three groups, a one-way Analysis of Variance (ANOVA) was calculated for each ROI based on the individual maps. Group analyses were thresholded using false discovery rate $(\mathrm{FDR})$ correction $(P<0.05)$.

\section{ReHo ANALYSIS}

Following procedures from a previous study (Chao-Gan and Yu-Feng, 2009), a whole brain map of ReHo values was calculated, voxel-wise, for each participant before spatial smoothing. In order to reduce the effects of variability across participants, 
Table 2 | Seed regions of interest (ROIs) and their MNI coordinates.

\begin{tabular}{|c|c|c|c|c|c|c|c|}
\hline \multirow[t]{2}{*}{ ROI (radius, $10 \mathrm{~mm}$ ) } & \multicolumn{3}{|c|}{ Left } & \multicolumn{3}{|c|}{ Right } & \multirow[t]{2}{*}{ Reference } \\
\hline & $\mathbf{x}$ & $\mathbf{y}$ & $\mathbf{z}$ & $\mathbf{x}$ & $\mathbf{y}$ & $\mathbf{z}$ & \\
\hline Caudate & -12 & 6 & 15 & 15 & 9 & 21 & $\begin{array}{l}\text { Bartels and Zeki (2000, 2004), Aron etal. (2005), Ortigue et al. (2007), Xu } \\
\text { etal. (2011), Acevedo et al. (2012) }\end{array}$ \\
\hline TPJ & -57 & -42 & 18 & 51 & -39 & 24 & Bartels and Zeki $(2000,2004)$, Ortigue et al. $(2007,2010)$ \\
\hline PCC & -6 & -45 & 21 & 8 & -44 & 24 & $\begin{array}{l}\text { Bartels and Zeki (2000, 2004), Aron etal. (2005), Ortigue et al. (2007), } \\
\text { Fisher et al. (2010), Acevedo etal. (2012) }\end{array}$ \\
\hline
\end{tabular}

the ReHo value of each voxel was normalized by dividing it by the mean whole-brain ReHo value of each participant (Chao-Gan and Yu-Feng, 2009; Wu et al., 2009; Liu et al., 2011; Zhang et al., 2012). The individual ReHo maps were compared across the three groups by using a ANOVA with FDR correction $(P<0.05)$.

\section{CORRELATION ANALYSIS BETWEEN rSFMRI AND BEHAVIOR}

To investigate brain-behavior relationships we conducted simple regression analyses, regressing either $\mathrm{ReHo} / \mathrm{FC}$ on the length of time in love (in the LG) or the lovelorn duration since breakup (in the ELG). Individual ReHo $z$-values were extracted from small ROI spheres (6 $\mathrm{mm}$ radius) placed where we found differences in the previous ReHo analyses across the three groups. The individual FC $z$-values were extracted from ROIs based on results from the comparison of FC across groups (FDR, $P<0.05$ ).

\section{RESULTS}

\section{REGIONAL HOMOGENEITY (ReHo) DIFFERENCES BETWEEN GROUPS}

Results showed that ReHo was significantly increased in the LG in the left dorsal anterior cingulate cortex (dACC) $[\mathrm{LG}>\mathrm{SG}$, peak coordinates $(-6,18,33)$; LG $>$ ELG, peak coordinates $(-6,18,30)]$. Furthermore, significant reduced ReHo was found in the ELG in the left caudate nucleus [LG > ELG, peak coordinates ($15,9,21)$; SG > ELG peak coordinates $(-18,9,24)]$ and right caudate nucleus [LG > ELG, peak coordinates $(18,9,21)$; SG > ELG, peak coordinates $(18,12,18)$ ] (See Figure 1).

\section{FUNCTIONAL CONNECTIVITY (FC) DIFFERENCES BETWEEN GROUPS}

The between-group comparison results of FC showed that the LG (in comparison to the SG) had significantly increased FC between the dACC seed and insula, NAC, and amygdala; between the insula seed and NAC, caudate nucleus, and amygdala; between the caudate seed and dACC, and insula; between the TPJ seed and ventromedial prefrontal cortex (vMPFC), and dorsal medial prefrontal cortex (dMPFC); and between the posterior cingulate cortex (PCC) seed and the inferior parietal lobe, MPFC, precuneus, and temporal lobe (See Figure 2; Table 3).

In comparison to the ELG, the LG also showed significantly increased FC between the dACC seed and insula; between the caudate nucleus seed and insula; between the TPJ seed and vMPFC, and AMPFC; and between the PCC seed and inferior parietal lobe, MPFC, precuneus, and temporal lobe (See Table 4).

In comparison to the SG, the ELG showed significantly increased FC between the dACC seed and insula, amygdala, caudate nucleus, and NAC; between the caudate nucleus seed and $\mathrm{AACC}$, and insula; between the TPJ seed and vMPFC, and dMPFC; between the PCC seed and inferior parietal lobe, MPFC, precuneus, and temporal lobe (See Table 5).

\section{CORRELATION BETWEEN rSfMRI AND BEHAVIOR}

Regression analyses showed that while ReHo of the left dACC ($6,18,33$ ) significantly increased with the length of time in love in the LG, it was significantly decreased with the lovelorn duration of time since breakup of romantic relationship in the ELG. Furthermore, while ReHo of the bilateral caudate nucleus was not correlated with the length of time in love in the LG, it was significantly positively correlated with lovelorn duration of time since breakup in the ELG (Figure 3).

Regression analyses of FC and behavioral data showed that FC (dACC-insula, dACC-amygdala, dACC-NAC, insula-amygdala, insula-caudate, insula-NAC, TPJ-vMPFC, TPJ-dMPFC, PCCprecuneus, PCC-inferior parietal lobe, PCC-MPFC) was significantly positively correlated with length of time in love in the LG, and significantly negatively correlated with the lovelorn duration of time since breakup in the ELG (Figure 4).

\section{DISCUSSION}

Although previous task-fMRI studies have preliminarily identified romantic love-related brain networks (Aron et al., 2005; Fisher et al., 2010; Xu et al., 2011), it remained unclear whether romantic love can affect the functional architecture of the brain. In the present study, we computed both ReHo and FC using rsfMRI data across three groups of participants (LG, "in-love" group who were currently intensely in love; ELG, "ended-love" group who recently ended a romantic relationship and were not currently in love; and SG, "single" group who had never fallen in love with anyone).

ReHo analysis results showed significantly increased ReHo of the left dACC in the in-love group (LG > SG, LG > ELG). Furthermore, the ReHo of the left dACC was positively correlated with 


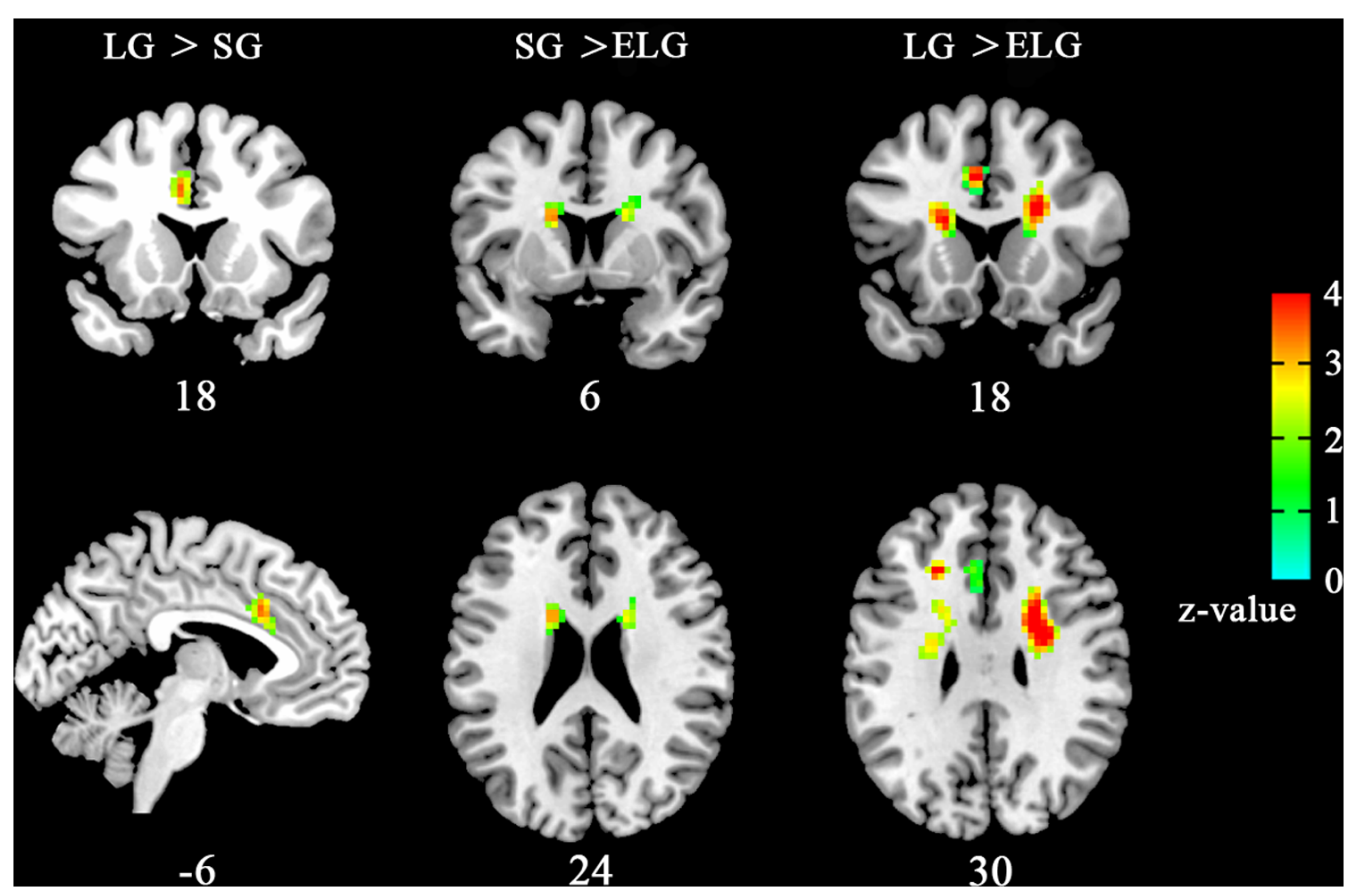

FIGURE 1 | Brain areas with altered ReHo the in-love group (LG) and ended-love group (ELG). Significantly increased regional homogeneity (ReHo) was found in the left dorsal anterior cingulate cortex (dACC; $-6,18,33)$ in the $L G(L G>S G)$, but reduced ReHo was found in the left caudate nucleus [ELG < SG, $(-15,9,21)$; ELG $<$ LG, $(-18,9,24)$ ] and the right caudate nucleus $[E L G<S G$, $(18,9,2) ; E L G<L G$, $(18,12,18)$ ] in the ELG. All resultants were corrected by FDR correction $(P<0.05)$. *Coordinates in MNI space. the length of time in love in the LG, and was negatively correlated with lovelorn duration in the ELG, suggesting that the ReHo of the left dACC may be closely related to the state of falling in love. At the same time, the ReHo of the bilateral caudate nucleus was significantly decreased in ELG (ELG $<$ SG, ELG $<$ LG), and was positively correlated with lovelorn duration in the ELG, suggesting that ReHo of the caudate nucleus may be closely related to the effects of ending a love relationship.

Results of FC showed that the lover group had significantly increased FC (LG > SG, LG > ELG) within the reward, motivation, and emotion regulation brain network (including the dACC, caudate nucleus, NAC, and insula) as well as in the social cognition network (including the TPJ, PCC, mPFC, precuneus, and inferior parietal lobe). Comparable to the ReHo analysis results (in the left dACC), FCs in both networks were significantly positively correlated with the length of time in love in the LG, as well as negatively correlated with lovelorn duration in the ELG, suggesting that falling in love may also be associated with increased connectivity within certain brain networks.

\section{ROMANTIC LOVE AND THE REWARD, MOTIVATION AND EMOTION REGULATION NETWORK}

The ACC, caudate nucleus, amygdala, NAC, and insula are core components of the brain systems that play an important role in the processing of sensory and emotional information, reward, and motivational processes (Mogenson etal., 1980). In the present study, we found significant increased FC in the LG (LG > SG, LG > ELG) between the ACC, caudate nucleus, amygdala, NAC, and insula. This may imply that romantic love may change the function of the reward, motivation, and emotion regulation brain network.

The dACC plays a key role in monitoring conflict through information processing, and compensatory adjustments in cognitive control (Botvinick et al., 2004). In fact, some researchers have found increased activation in the ACC individuals with greater social insight and maturity (Lane et al., 1998; Bush et al., 1999). Bartels and Zeki (2000) suggested that the dACC is implicated in states of happiness, interoception (i.e., attention to one's own emotional state), and also in social interactions that involve assessing one's own and other people's emotions and states of mind. For example, Aron etal. (2005) found that length of time in love is positively correlated with dACC activation when watching photographs of a romantic partner.

The caudate nucleus is highly innervated by dopaminergic neurons that originate mainly from the VTA and substantia nigra pars compacta $(\mathrm{SNc})$. The caudate nucleus is associated with reward detection, expectation, representation of goals, and integration of sensory inputs (Aron et al., 2005; Lauwereyns, 2006).

The amygdala is mainly responsible for processing information related to fear, sadness and aggression, and mediating emotional learning (Dalgleish, 2004). Activation level in the amygdala has been shown to decrease when participants view photos of their sweetheart (Bartels and Zeki, 2000, 2004; Aron et al., 2005; Xu et al., 2011). Furthermore, the NAC, a brain area coinciding with cortical areas rich in dopamine and oxytocin receptors, is an 

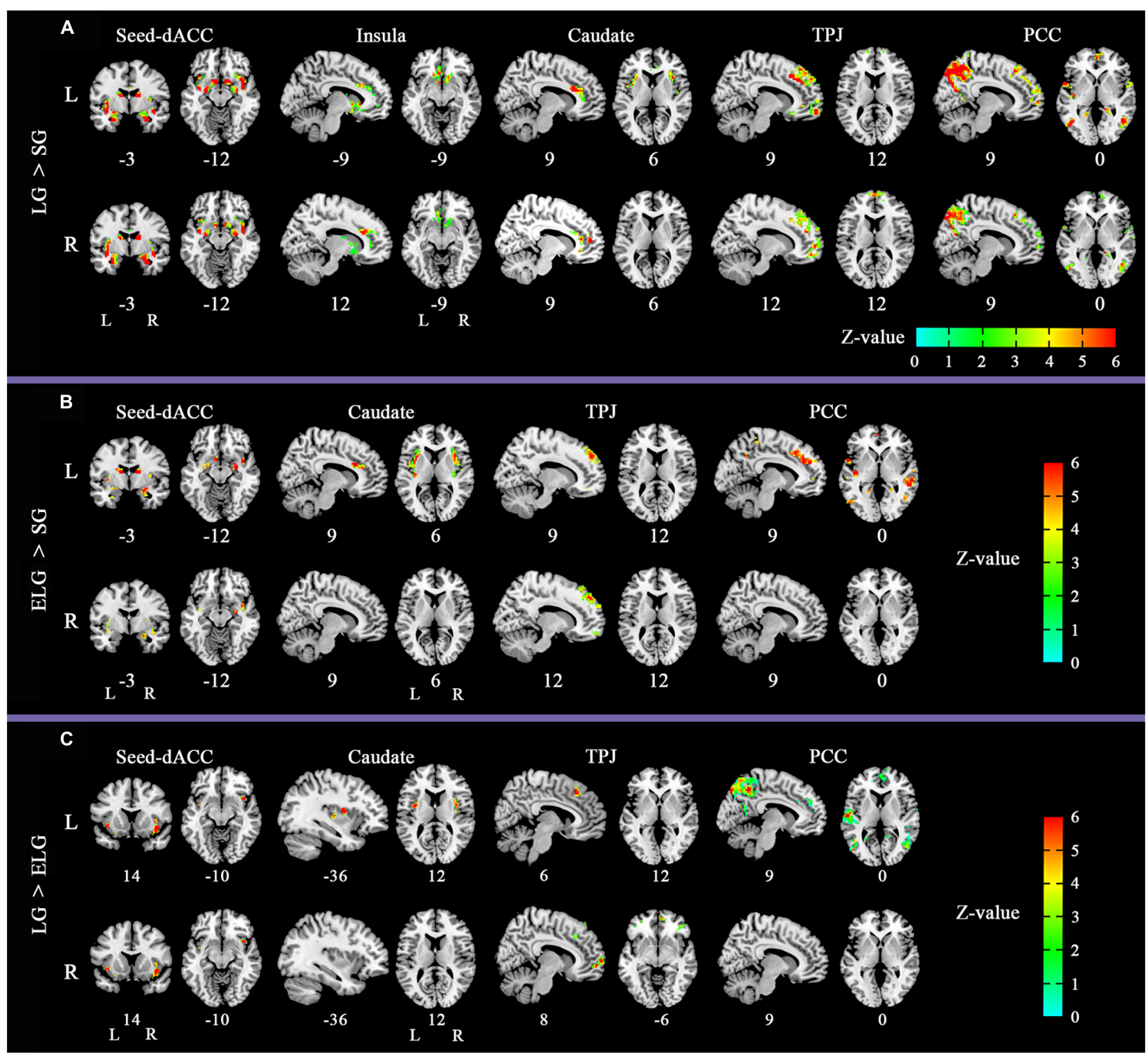

FIGURE 2 | Altered functional connectivity (FC) pattern in comparison across the three groups. Images of $\mathrm{FC}$ demonstrates differences in resting-state $F C$ between groups (A) $L G>S G$, (B) $E L G>S G$, (C) $L G>E L G$ (see Tables 3-5 for complete results). For each comparison, the top row shows the FC pattern of the left hemisphere and the bottom row shows the right hemisphere. $L$, left; $R$, right. All resultants were corrected by FDR correction $(P<0.05)$. ${ }^{*}$ Coordinates in MNI space. important part of the reward pathway that plays a central role in the visual perception of pleasant stimuli (Aharon et al., 2001; Sabatinelli et al., 2007). It is involved in both natural and abnormal reward processes (Breiter et al., 2001; Knutson et al., 2005; Baler and Volkow, 2006; Knutson and Wimmer, 2007; Cooper and Knutson, 2008). Within the context of love, the recruitment of the NAC is therefore consistent with notions of romantic love as 'a desire for union with another' (Hatfield and Rapson, 1993; Acevedo et al., 2012).

The insula has been ascribed a role in representing subjective feelings, attention, cognitive choices, intentions, time perception, awareness of sensations, movements (Farrer and Frith, 2002;
Critchley et al., 2004; Tsakiris et al., 2007), the visual image of the self (Devue et al., 2007), subjective expectations (Seymour et al., 2004; Preuschoff et al., 2008), and the trustworthiness of other individuals (Craig, 2002). Studies of romantic love report that the activity in the insula is increased when participants view their romantic partner's picture (Bartels and Zeki, 2004; Ortigue et al., 2007; Fisher et al., 2010).

Previous research has demonstrated that spatially remote brain regions do not function independently, but rather, interact with one another during cognitive processing. For example, when individuals engage in a reinforcement learning paradigm relating to judging the positive or negative value of visual stimuli both the 
Table 3 | Significant regions in the comparison of functional connectivity (FC) between the LG and SG.

\begin{tabular}{lllllll}
\hline Seed ROI & $\begin{array}{l}\text { Location of } \\
\text { naximum }\end{array}$ & $\begin{array}{l}\text { Cluster } \\
\text { size }\end{array}$ & \multicolumn{2}{c}{ MNI coordinates } & \\
\cline { 3 - 6 } & intensity voxel & (Voxels) & x & $y$ & z & z-value \\
\hline
\end{tabular}

\section{LG > SG}

Left dACC

$\begin{array}{llrlrl}\text { Left insula } & 221 & -36 & 0 & 0 & 4.93 \\ \text { Right insula } & 305 & 33 & 12 & -15 & 5.22 \\ \text { Left NAC } & 28 & -12 & 6 & -12 & 3.67 \\ \text { Left amygdala } & 49 & -21 & 0 & -12 & 3.75 \\ \text { Right amygdala } & 51 & -24 & -6 & -18 & 4.04\end{array}$

Right dACC

Left insula

335

$\begin{array}{llll}-36 & -3 & -9 & 6.09\end{array}$

Right insula $\quad 337$

Right NAC $\quad 28$

Left amygdala $\quad 80$

$\begin{array}{llll}39 & 0 & -12 & 5.82\end{array}$

Right amygdala $\quad 95$

$\begin{array}{llll}9 & 9 & -12 & 4.25\end{array}$

$\begin{array}{llll}-30 & -3 & -21 & 5.33\end{array}$

$\begin{array}{llll}-27 & 0 & -18 & 4.3\end{array}$

Left insula

$\begin{array}{llrlll}\text { Left caudate } & 89 & -12 & 18 & -3 & 3.93 \\ \text { Right caudate } & 65 & 15 & 21 & -6 & 4.16 \\ \text { Left amygdala } & 80 & -21 & 0 & -12 & 3.79\end{array}$

Right insula

$\begin{array}{llrccc}\text { Left NAC } & 20 & -12 & 9 & -12 & 1.44 \\ \text { Right NAC } & 25 & 12 & 9 & -9 & 2.51 \\ \text { Left caudate } & 160 & -12 & -9 & 18 & 4.23 \\ \text { Right caudate } & 188 & 18 & 21 & -3 & 3.49 \\ \text { Left amygdala } & 59 & -27 & -6 & -18 & 5.34 \\ \text { Right amygdala } & 69 & 30 & -9 & -12 & 4.07\end{array}$

Left caudate

$\begin{array}{llllll}\text { Right dACC } & 58 & 9 & 21 & 24 & 5.09\end{array}$

$\begin{array}{llllll}\text { Left insula } & 50 & -45 & 6 & 3 & 4.25\end{array}$

$\begin{array}{llllll}\text { Right insula } & 73 & 48 & 9 & -6 & 4.9\end{array}$

Right caudate

\begin{tabular}{|lllclll}
\hline \multirow{2}{*}{ Left TPJ } & Right dACC & 34 & 12 & 27 & 21 & 3.6 \\
\cline { 2 - 5 } & & & & & & \\
& Left vMPFC & 39 & -12 & 63 & -3 & 4.89 \\
& Right vMPFC & 73 & 9 & 63 & -12 & 4.21 \\
& Left dMPFC & 362 & 0 & 30 & 39 & 5.61 \\
& Right dMPFC & 305 & 6 & 30 & 39 & 5.01 \\
\hline Right TPJ & & & & & & \\
& Left vMPFC & 103 & 0 & 60 & -12 & 4.3 \\
& Right vMPFC & 93 & 12 & 54 & -12 & 4.31 \\
& Left dMPFC & 365 & -3 & 27 & 39 & 5.4 \\
& Right dMPFC & 192 & 12 & 45 & 24 & 4.29 \\
\hline
\end{tabular}

(Continued)
Table 3 | Continued

\begin{tabular}{|c|c|c|c|c|c|c|}
\hline \multirow[t]{2}{*}{ Seed ROI } & \multirow{2}{*}{$\begin{array}{l}\text { Location of } \\
\text { naximum } \\
\text { intensity voxel }\end{array}$} & \multirow{2}{*}{$\begin{array}{l}\text { Cluster } \\
\text { size } \\
\text { (Voxels) }\end{array}$} & \multicolumn{3}{|c|}{ MNI coordinates } & \multirow[b]{2}{*}{ z-value } \\
\hline & & & $\mathbf{x}$ & $\mathbf{y}$ & $\mathbf{z}$ & \\
\hline \multicolumn{7}{|l|}{ Left PCC } \\
\hline & $\begin{array}{l}\text { Left inferior } \\
\text { parietal }\end{array}$ & 342 & -27 & -48 & 51 & 5.01 \\
\hline & $\begin{array}{l}\text { Right inferior } \\
\text { parietal }\end{array}$ & 109 & 30 & -48 & 54 & 4.97 \\
\hline & Left MPFC & 142 & 0 & -3 & 54 & 3.96 \\
\hline & Right MPFC & 377 & 6 & 27 & 54 & 4.11 \\
\hline & Left precuneus & 560 & -3 & -57 & 66 & 5.57 \\
\hline & $\begin{array}{l}\text { Right } \\
\text { precuneus }\end{array}$ & 515 & 9 & -60 & 57 & 4.53 \\
\hline & $\begin{array}{l}\text { Left temporal } \\
\text { lobe }\end{array}$ & 531 & -45 & -63 & -9 & 5.15 \\
\hline & $\begin{array}{l}\text { Right temporal } \\
\text { lobe }\end{array}$ & 772 & 48 & -15 & -18 & 5.79 \\
\hline \multicolumn{7}{|l|}{ Right PCC } \\
\hline & $\begin{array}{l}\text { Left inferior } \\
\text { parietal }\end{array}$ & 238 & -39 & -57 & 60 & 4.83 \\
\hline & $\begin{array}{l}\text { Right inferior } \\
\text { parietal }\end{array}$ & 80 & 30 & -48 & 54 & 4.15 \\
\hline & Left MPFC & 63 & 0 & 3 & 54 & 4.04 \\
\hline & Left precuneus & 387 & -6 & -63 & 66 & 6.06 \\
\hline & $\begin{array}{l}\text { Right } \\
\text { precuneus }\end{array}$ & 327 & 6 & -60 & 51 & 4.27 \\
\hline & $\begin{array}{l}\text { Left temporal } \\
\text { lobe }\end{array}$ & 254 & -60 & -12 & 9 & 5.4 \\
\hline & $\begin{array}{l}\text { Right temporal } \\
\text { lobe }\end{array}$ & 270 & 51 & -51 & -21 & 5.19 \\
\hline \multicolumn{7}{|l|}{$\mathbf{L G}<\mathbf{S G}$} \\
\hline & None & & & & & \\
\hline
\end{tabular}

NAC, nucleus accumbens; MPFC, medial prefrontal cortex; $V M P F C$, ventral medial prefrontal cortex; $A M P F C$, dorsomedial prefrontal cortex. FDR correction $(P<0.05)$ for multiple comparisons, MNI coordinates $(x, y, z)$ for the most significant voxel in a cluster.

amygdala and the NAC are involved in signal processing, which is then passed on to the insula (Reynolds and Zahm, 2005; Paulus and Stein, 2006). Unconditioned and conditioned sexual incentive cues are also known to be processed in the caudate nucleus, which expects, detects, and represents the reward values of the external stimulus, and outputs them to the insula (Cacioppo et al., 2012). The control of a goal-directed behavior will involve both the insula, representing awareness, and the ACC, representing the control of directed effort (Craig, 2009). Thus, increased FC between these regions in a group of lovers may be the result of frequent efforts to monitor their own emotional state, as well as their lovers' emotional state, monitoring conflicts while adjusting 
Table 4 | Significant regions in the comparison of FC between the LG and ELG.

\begin{tabular}{|c|c|c|c|c|c|c|}
\hline \multirow[t]{2}{*}{ Seed ROI } & \multirow{2}{*}{$\begin{array}{l}\text { Location of } \\
\text { maximum } \\
\text { intensity voxel }\end{array}$} & \multirow{2}{*}{$\begin{array}{l}\text { Cluster } \\
\text { size } \\
\text { (Voxels) }\end{array}$} & \multicolumn{3}{|c|}{ MNI coordinates } & \multirow[t]{2}{*}{ z-value } \\
\hline & & & $\mathbf{x}$ & $\mathbf{y}$ & $\mathbf{z}$ & \\
\hline \multicolumn{7}{|l|}{ LG > ELG } \\
\hline \multicolumn{7}{|l|}{ Left dACC } \\
\hline & Left insula & 34 & -39 & 6 & 0 & 2.81 \\
\hline & Right insula & 78 & 36 & 18 & 0 & 3.62 \\
\hline \multicolumn{7}{|c|}{ Right dACC } \\
\hline & Left insula & 18 & -45 & 6 & 0 & 2.39 \\
\hline & Right insula & 44 & 36 & 24 & 0 & 3.02 \\
\hline \multicolumn{7}{|c|}{ Left caudate } \\
\hline & Left insula & 13 & -36 & 0 & 12 & 3.18 \\
\hline & Right insula & 29 & 39 & 0 & 15 & 3.49 \\
\hline \multicolumn{7}{|l|}{ Left TPJ } \\
\hline & Right dMPFC & 189 & 6 & 27 & 48 & 3.22 \\
\hline \multicolumn{7}{|l|}{ Right TPJ } \\
\hline & Left vMPFC & 72 & 9 & 66 & 6 & 3.15 \\
\hline & Left dMPFC & 39 & -12 & 18 & 48 & 2.66 \\
\hline & Right dMPFC & 37 & 12 & 30 & 42 & 2.27 \\
\hline \multicolumn{7}{|l|}{ Left PCC } \\
\hline & $\begin{array}{l}\text { Right inferior } \\
\text { parietal }\end{array}$ & 35 & 36 & -48 & 48 & 2.38 \\
\hline & Left MPFC & 47 & -3 & 36 & 27 & 3.31 \\
\hline & Left precuneus & 195 & -12 & -78 & 48 & 2.69 \\
\hline & $\begin{array}{l}\text { Right } \\
\text { precuneus }\end{array}$ & 290 & 6 & -60 & 48 & 3.35 \\
\hline & $\begin{array}{l}\text { Right temporal } \\
\text { lobe }\end{array}$ & 116 & 54 & -66 & 21 & 2.86 \\
\hline
\end{tabular}

\section{LG $<$ ELG}

None

FDR correction $(P<0.05)$, MNI coordinates $(x, y, z)$ for the most significant voxel in a cluster.

cognitive strategies in order to resolve conflicts so as to maintain their romantic relationship.

\section{ROMANTIC LOVE AND THE SOCIAL COGNITION NETWORK}

Our findings show that the LG had significantly increased FC compared to the SG and ELG between the TPJ seed and vMPFC, and AMPFC; and between the PCC seed and inferior parietal, MPFC, precuneus, and temporal lobe. Moreover, FC was significantly positively related to the length of time in love in the LG. These regions are part of a social cognition network, which contains brain areas activated during social interaction and areas involved in general cognition and attention. Regions activated during social interaction include the TPJ, vMPFC, and dMPFC. This network has been consistently associated with social, moral and 'theory of mind' tasks (the
Table 5 | Significant regions in the comparison of FC between the ELG and SG.

\begin{tabular}{|c|c|c|c|c|}
\hline \multirow[t]{2}{*}{ Seed $F$} & \multirow{2}{*}{$\begin{array}{l}\text { Location of } \\
\text { maximum } \\
\text { intensity voxel }\end{array}$} & \multirow{2}{*}{$\begin{array}{l}\text { Cluster } \\
\text { size } \\
\text { (Voxels) }\end{array}$} & MNI coordinates & \multirow[t]{2}{*}{ z-value } \\
\hline & & & $\mathbf{x}$ & \\
\hline
\end{tabular}

ELG > SG

Left dACC

$\begin{array}{llrccc}\text { Left insula } & 76 & -36 & -9 & 9 & 3.57 \\ \text { Right insula } & 77 & 36 & -24 & 21 & 4.64 \\ \text { Left NAC } & 20 & -12 & 9 & -12 & 2.53 \\ \text { Left amygdala } & 29 & -24 & -6 & -12 & 3.7 \\ \text { Right amygdala } & 41 & 30 & -6 & -12 & 5.41\end{array}$

Right dACC

$\begin{array}{llrlll}\text { Left insula } & 226 & -36 & -6 & -6 & 4.47 \\ \text { Right insula } & 241 & 33 & -18 & -18 & 5.29 \\ \text { Left amygdala } & 30 & -27 & -6 & -15 & 3.46 \\ \text { Right amygdala } & 48 & 27 & -6 & -12 & 3.85\end{array}$

Left caudate

\begin{tabular}{|c|c|c|c|c|c|c|}
\hline & Left dACC & 35 & -6 & 21 & 30 & 3.24 \\
\hline & Right dACC & 43 & 6 & 18 & 27 & 5.35 \\
\hline & Left insula & 139 & -39 & -15 & 0 & 4.81 \\
\hline & Right insula & 121 & 39 & 15 & -3 & 5.26 \\
\hline \multicolumn{7}{|l|}{ Left TPJ } \\
\hline & Left dMPFC & 152 & -6 & 48 & 48 & 5.61 \\
\hline & Right dMPFC & 73 & 12 & 51 & 39 & 5.28 \\
\hline \multicolumn{7}{|l|}{ Right TPJ } \\
\hline & Left vMPFC & 32 & -3 & 57 & -15 & 4.26 \\
\hline & Left dMPFC & 134 & -9 & 57 & 36 & 4.76 \\
\hline & Right dMPFC & 82 & 12 & 48 & 42 & 4.7 \\
\hline \multicolumn{7}{|l|}{ Left PCC } \\
\hline & $\begin{array}{l}\text { Left inferior } \\
\text { parietal }\end{array}$ & 75 & -54 & -48 & 42 & 5.29 \\
\hline & $\begin{array}{l}\text { Right inferior } \\
\text { parietal }\end{array}$ & 42 & 57 & -42 & 48 & 4.48 \\
\hline & Left MPFC & 280 & -3 & 36 & 36 & 5.61 \\
\hline & Right MPFC & 261 & 3 & 57 & 36 & 5 \\
\hline & Left precuneus & 37 & -15 & -39 & 66 & 4.43 \\
\hline & $\begin{array}{l}\text { Left temporal } \\
\text { lobe }\end{array}$ & 165 & -42 & -15 & -3 & 5.38 \\
\hline & $\begin{array}{l}\text { Right temporal } \\
\text { lobe }\end{array}$ & 421 & 57 & -18 & -15 & 5.37 \\
\hline
\end{tabular}

$\mathbf{L G}<\mathbf{E L G}<\mathbf{S G}$

None

FDR correction $(P<0.05)$, MNI coordinates $(x, y, z)$ for the most significant voxel in a cluster. 

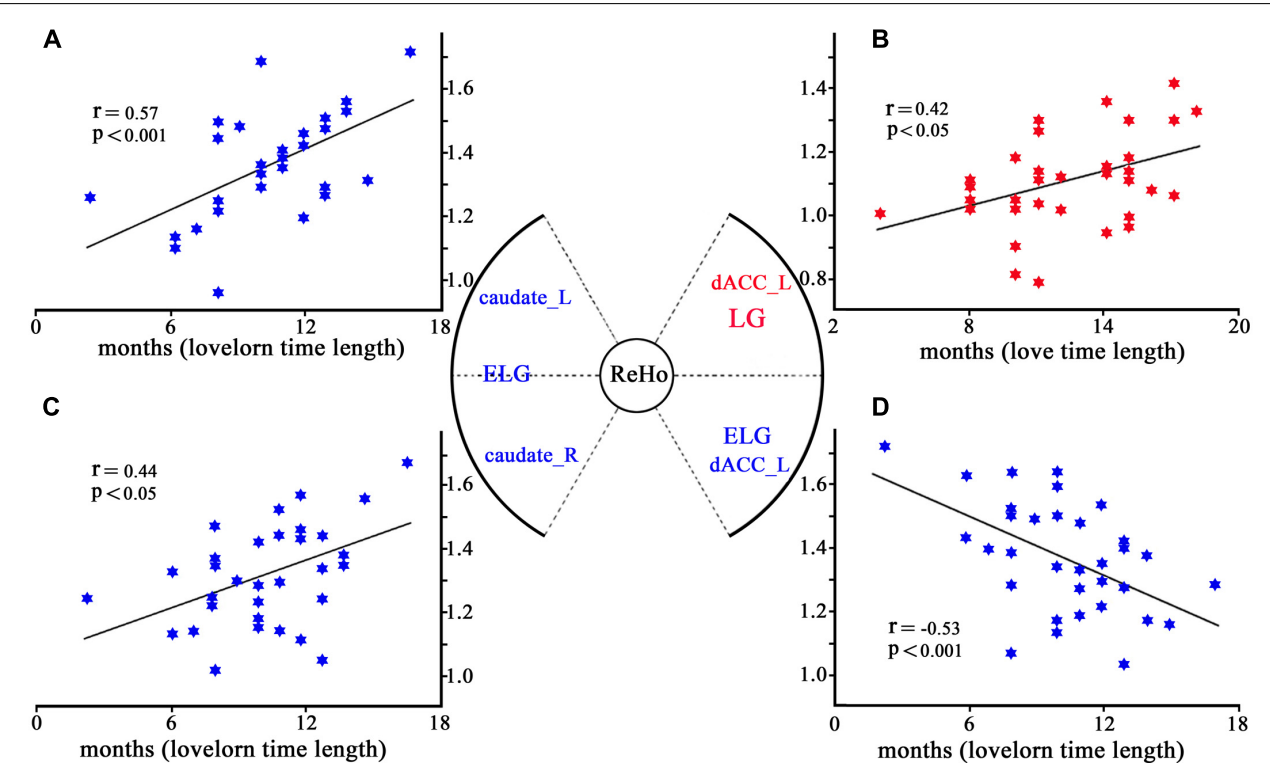

FIGURE 3 | Correlation between ReHo and the length of time in-love (in LG) or the lovelorn duration since the breakup of romantic relationship (in ELG). (A) depicts ReHo in the left caudate nucleus $(-18,9$, 24), which was significantly positively correlated with the length of time since the romantic relationship breakup in ELG; (B) shows ReHo in left dACC $(-6,18,33)$, which was significantly negatively correlated with the length of time in love of LG; (C) demonstrates ReHo in the right caudate nucleus $(18,12,18)$, which was significantly positively correlated with the length of time since the romantic relationship breakup in ELG; (D) shows ReHo of left dACC $(-6,18,30)$, which was significantly positively correlated with the length of time since the romantic relationship breakup of ELG. ${ }^{*}$ Coordinates in MNI space.

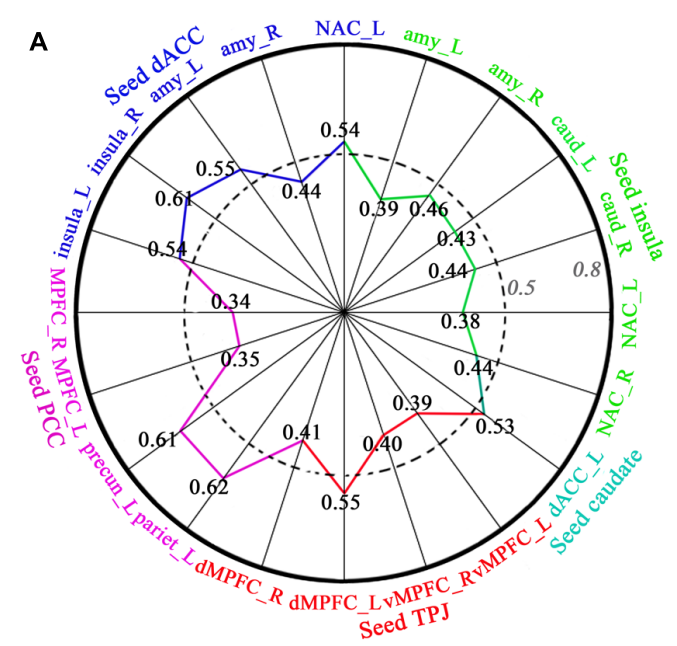

FIGURE 4 | Correlation between FC and length of time in-love (in LG) and the lovelorn duration since breakup of romantic relationship (in ELG). (A) depicts the significant positive correlation between $F C$ and the length of time in-love in LG; (B) shows the significant negative correlation between FC and the lovelorn duration since the breakup of romantic relationship in ELG. Intensity of FC was extracted from ROls (small sphere of $6 \mathrm{~mm}$ radius, the

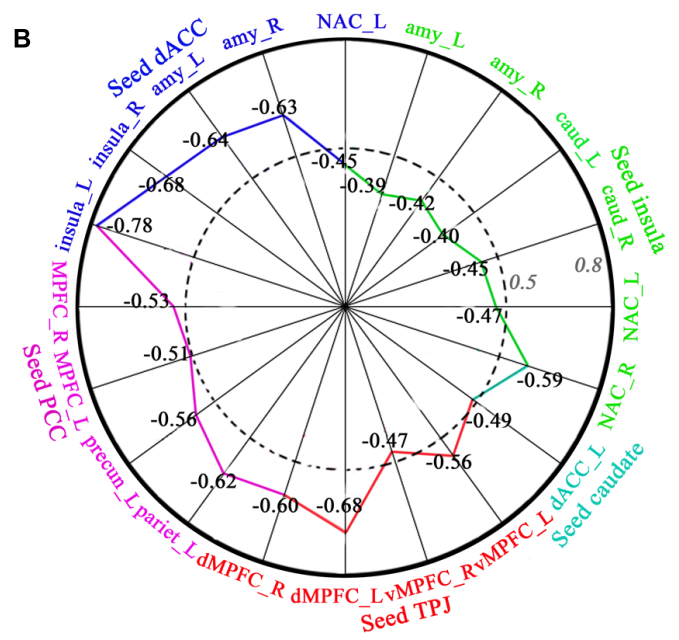

center coordinates are listed in Table 3) based on the results of the FC comparison between the LG and SG (FDR, $P<0.05)$. The absolute value of the correlation coefficient increases gradually from the center to the circumference. Numbers represent the correlation coefficient, and the colors represent the corresponding brain regions. These are only the results of the right hemisphere. All correlations shown were significant $(P<0.05)$. ability to determine other people's emotions and intentions) (Frith and Frith, 1999; Brunet etal., 2000; Gallagher and Frith, 2003), and has been associated with social trustworthiness (Winston etal., 2002), facial expressions (Winston et al., 2002), moral judgment (Greene and Haidt, 2002; Moll etal., 2002), and attention to one's own emotions (Lane et al., 1997;
Gusnard et al., 2001). Brain regions generally involved in social cognition include the PCC and inferior parietal and middle temporal cortices, which play a role in cognitive attention, and short-and long-term memory (Beauregard et al., 1998; Maddock, 1999; Cabeza and Nyberg, 2000; Buckner etal., 2008). 


\section{DOPAMINE, OXYTOCIN, VASOPRESSIN, AND ROMANTIC LOVE}

Our results show increased FC between subcortical regions in lovers (between the caudate nucleus, NAC, amygdala, and insula), areas closely related to the mesolimbic dopaminergic system. The mesolimbic dopaminergic system is suggested to be a mechanism by which humans and other mammals enact behaviors that maintain and protect their pair-bonds (Winslow et al., 1993; Sue Carter et al., 1995; Wang et al., 1997; Aragona et al., 2003). Dopamine has also been shown to play an important role in the romantic love of humans (Acevedo et al., 2012).

The VTA is centrally placed in a wider motivational/reward network associated with behaviors necessary for survival (Camara et al., 2009). It is considered a central platform for pleasurable feelings and pair-bonding (Ortigue etal., 2010). The NAC has been implicated in the interaction between the neurotransmitter dopamine and the neuropeptide oxytocin (Liu and Wang, 2003). Both oxytocin and vasopressin have been shown to be crucially involved in romantic love and bonding (Kendrick, 2000; Fisher et al., 2006; Gonzaga et al., 2006). Oxytocin is released during sexual activity and mating, and may be the neurochemical mechanism for the anxiolytic effect of mating (Waldherr and Neumann, 2007). Recently, Rilling et al. (2012) suggested that both oxytocin and vasopressin were associated with increased FC between amygdala and the anterior insula, possibly enhancing the amygdala's ability to elicit visceralsomatic markers in order to guide decisionmaking. The increased FC observed between subcortical regions in lovers may therefore reflect the neurophysiological interaction between oxytocin, dopamine, and/or vasopressin while in a state of love.

\section{EFFECT OF LOVELORN STATE ON BRAIN NETWORKS}

Although we did not intentionally investigate the effect of lovelorn in the present study, we found that ReHo of the bilateral caudate nucleus was significantly decreased in the ELG $(E L G<S G$, ELG $<$ LG) and was also correlated with the lovelorn duration of time since breakup of romantic relationship in the ELG (not correlated with the length of time in love in the LG).

As discussed before, the caudate nucleus is associated with detection of reward, expectation, representation of goals, and integration of sensory input (Aron etal., 2005; Lauwereyns, 2006). Deep brain stimulation of the caudate nucleus has been shown to improve symptoms of anxiety disorder and major depression (Aouizerate et al., 2004). Neurochemical studies have demonstrated that these effects may be mediated by non-selective corticotropic-releasing systems. Being in a relationship has been associated with elevated CRF mRNA in the bed nucleus of the stria terminalis in nerve fibers originating from the amygdal (Bosch et al., 2008). Therefore, the caudate nucleus may be very important for relieving symptoms of anxiety and depression. An elevated FC between regions involved in the anxiety-relief system after breaking up may be a sign of recovery.

\section{LIMITATIONS}

The chosen approach was a cross-sectional design, conducted via a comparison across three independent subject groups. Further longitudinal studies will be necessary to verify and extend the findings of the present study. One challenge for longitudinal studies of romantic love may be that romantic relationships are not easily controlled inside a laboratory. Another possible limitation of this study is that we do not know exactly whether love-related alterations are adaptation, or maladaptation in lovers. From an evolutionary perspective, romantic love can be seen as a mechanism developed for choosing a partner that offers the best chances for survival to the offspring (de Boer et al., 2012). We therefore propose that love-related alterations in $\mathrm{FC}$ or ReHo reflect this mechanism, as it is a correlate of the individuals' effort when trying to maintain an important inter-personal relationship. However, based on the present results we cannot directly test this hypothesis. In future studies, cognitive and behavioral tasks should therefore be employed to further investigate the relationship between resting brain functional alterations and love-related behaviors.

\section{CONCLUSION}

In summary, we calculated Regional Homogeneity (ReHo) and functional connectivity (FC) using resting state functional magnetic resonance imaging (rsfMRI) data to investigate romantic love-related brain functional topological changes. We found that love-related alterations included increased ReHo of the left dACC and increased FC within the reward, motivation, and emotion regulation network, as well as the social cognition network. We also found decreased ReHo of the bilateral caudate nucleus related to the ending of a romantic relationship.

This study provides the first empirical evidence of love-related alterations in the underlying functional architecture of the brain. Findings are in agreement with results from task-dependent fMRI studies, and complement well the functional findings of task-dependent fMRI studies. These results shed light on the underlying neurophysiological mechanisms of romantic love by investigating intrinsic brain activity, and demonstrate the possibility of applying a resting state approach for investigating romantic love.

\section{ACKNOWLEDGMENTS}

We thank Jie Yin for technical assistance in brain imaging data collection. This work was supported by grants from the National Natural Science Foundation of China (31230032, 31171083, 31471071), the Fundamental Research Funds for the Central Universities of China (WK2070000033) and the 100 Talents Program of The Chinese Academy of Sciences (BJ2070000047).

\section{REFERENCES}

Acevedo, B. P., and Aron, A. (2009). Does a long-term relationship kill romantic love? Rev. Gen. Psychol. 13, 59-65. doi: 10.1037/a0014226

Acevedo, B. P., Aron, A., Fisher, H. E., and Brown, L. L. (2012). Neural correlates of long-term intense romantic love. Soc. Cogn. Affect. Neurosci. 7, 145-159. doi: 10.1093/scan/nsq092

Aertsen, A. M., Gerstein, G. L., Habib, M. K., and Palm, G. (1989). Dynamics of neuronal firing correlation: modulation of "effective connectivity". J. Neurophysiol. 61, 900-917.

Aharon, I., Etcoff, N., Ariely, D., Chabris, C. F., O'Connor, E., and Breiter, H. C. (2001). Beautiful faces have variable reward value: $\mathrm{fMRI}$ and behavioral evidence. Neuron 32, 537-551. doi: 10.1016/S0896-6273(01)00491-3

Aouizerate, B., Cuny, E., Martin-Guehl, C., Guehl, D., Amieva, H., Benazzouz, A., et al. (2004). Deep brain stimulation of the ventral caudate nucleus in the treatment of obsessive-compulsive disorder and major depression: case report. J. Neurosurg. 101, 682-686. doi: 10.3171/jns.2004.101.4.0682 
Aragona, B. J., Liu, Y., Curtis, J. T., Stephan, F. K., and Wang, Z. (2003). A critical role for nucleus accumbens dopamine in partner-preference formation in male prairie voles. J. Neurosci. 23, 3483-3490.

Aron, A., and Aron, E. N. (1991). Love and Sexuality. Hillsdale: Lawrence Erlbaum Associates press.

Aron, A., Fisher, H., Mashek, D. J., Strong, G., Li, H., and Brown, L. L. (2005). Reward, motivation, and emotion systems associated with early-stage intense romantic love. J. Neurophysiol. 94, 327-337. doi: 10.1152/jn.00838.2004

Baler, R. D., and Volkow, N. D. (2006). Drug addiction: the neurobiology of disrupted self-control. Trends Mol. Med. 12, 559-566. doi: 10.1016/j.molmed.2006.10.005

Bartels, A., and Zeki, S. (2000). The neural basis of romantic love. Neuroreport 11, 3829-3834. doi: 10.1097/00001756-200011270-00046

Bartels, A., and Zeki, S. (2004). The neural correlates of maternal and romantic love. Neuroimage 21, 1155-1166. doi: 10.1016/j.neuroimage.2003.11.003

Baumeister, R. F., Wotman, S. R., and Stillwell, A. M. (1993). Unrequited love: on heartbreak, anger, guilt, scriptlessness, and humiliation. J. Pers. Soc. Psychol. 64 377-394. doi: 10.1037/0022-3514.64.3.377

Beauregard, M., Leroux, J.-M., Bergman, S., Arzoumanian, Y., Beaudoin, G., Bourgouin, P., et al. (1998). The functional neuroanatomy of major depression: an fMRI study using an emotional activation paradigm. Neuroreport 9, 3253-3258. doi: 10.1097/00001756-199810050-00022

Bianchi-Demicheli, F., Grafton, S. T., and Ortigue, S. (2006). The power of love on the human brain. Soc. Neurosci. 1, 90-103. doi: 10.1080/17470910600976547

Biswal, B., Zerrin Yetkin, F., Haughton, V. M., and Hyde, J. S. (1995). Functional connectivity in the motor cortex of resting human brain using echo-planar mri. Magn. Reson. Med. 34, 537-541. doi: 10.1002/mrm.1910340409

Bosch, O. J., Nair, H. P., Ahern, T. H., Neumann, I. D., and Young, L. J. (2008) The CRF system mediates increased passive stress-coping behavior following the loss of a bonded partner in a monogamous rodent. Neuropsychopharmacology 34 , 1406-1415. doi: 10.1038/npp.2008.154

Botvinick, M. M., Cohen, J. D., and Carter, C. S. (2004). Conflict monitoring and anterior cingulate cortex: an update. Trends Cogn. Sci. (Regul. Ed.) 8, 539-546. doi: 10.1016/j.tics.2004.10.003

Breiter, H. C., Aharon, I., Kahneman, D., Dale, A., and Shizgal, P. (2001). Functional imaging of neural responses to expectancy and experience of monetary gains and losses. Neuron 30, 619-639. doi: 10.1016/S0896-6273(01)00303-8

Brunet, E., Sarfati, Y., Hardy-Baylé, M.-C., and Decety, J. (2000). A PET investigation of the attribution of intentions with a nonverbal task. Neuroimage 11, 157-166. doi: 10.1006/nimg.1999.0525

Buckner, R. L., Andrews-Hanna, J. R., and Schacter, D. L. (2008). The brain's default network. Ann. N. Y. Acad. Sci. 1124, 1-38. doi: 10.1196/annals.1440.011

Bush, G., Frazier, J. A., Rauch, S. L., Seidman, L. J., Whalen, P. J., Jenike, M. A., et al. (1999). Anterior cingulate cortex dysfunction in attention-deficit/hyperactivity disorder revealed by fMRI and the counting Stroop. Biol. Psychiatry 45, 15421552. doi: 10.1016/S0006-3223(99)00083-9

Buzsáki, G., and Draguhn, A. (2004). Neuronal oscillations in cortical networks. Science 304, 1926-1929. doi: 10.1126/science.1099745

Cabeza, R., and Nyberg, L. (2000). Neural bases of learning and memory: functional neuroimaging evidence. Curr. Opin. Neurol. 13, 415-421. doi: 10.1097/00019052200008000-00008

Cacioppo, S., Bianchi-Demicheli, F., Frum, C., Pfaus, J. G., and Lewis, J. W. (2012). The common neural bases between sexual desire and love: a multilevel kernel density fMRI analysis. J. Sex. Med. 9, 1048-1054. doi: 10.1111/j.17436109.2012.02651.x

Camara, E., Rodriguez-Fornells, A., Ye, Z., and Münte, T. F. (2009). Reward networks in the brain as captured by connectivity measures. Front. Neurosci. 3:350-362. doi: 10.3389/neuro.01.034.2009

Chao-Gan, Y., and Yu-Feng, Z. (2009). DPARSF: a MATLAB toolbox for "Pipeline" data analysis of resting-state fMRI. Front. Syst. Neurosci. 4:13. doi: 10.3389/fnsys.2010.00013

Chou, Y.-H., Panych, L. P., Dickey, C. C., Petrella, J. R., and Chen, N.-K. (2012). Investigation of long-term reproducibility of intrinsic connectivity network mapping: a resting-state fMRI study. Am. J. Neuroradiol. 33, 833-838. doi: 10.3174/ajnr.A2894

Clark, M. S., and Mills, J. (1979). Interpersonal attraction in exchange and communal relationships. J. Pers. Soc. Psychol. 37, 12-24. doi: 10.1037/0022-3514. 37.1 .12
Cooper, J. C., and Knutson, B. (2008). Valence and salience contribute to nucleus accumbens activation. Neuroimage 39, 538-547. doi: 10.1016/j.neuroimage.2007.08.009

Craig, A. D. (2002). How do you feel? Interoception: the sense of the physiological condition of the body. Nat. Rev. Neurosci. 3, 655-666. doi: 10.1038/ nrn894

Craig, A. D. (2009). How do you feel-now? The anterior insula and human awareness. Nat. Rev. Neurosci. 10, 59-70. doi: 10.1038/nrn2555

Critchley, H. D., Wiens, S., Rotshtein, P., Öhman, A., and Dolan, R. J. (2004). Neural systems supporting interoceptive awareness. Nat. Neurosci. 7, 189-195. doi: $10.1038 / \mathrm{nn} 1176$

Dalgleish, T. (2004). The emotional brain. Nat. Rev. Neurosci. 5, 583-589. doi: $10.1038 / \mathrm{nrn} 1432$

de Boer, A., Van Buel, E. M., and Ter Horst, G. J. (2012). Love is more than just a kiss: a neurobiological perspective on love and affection. Neuroscience 201, 114-124. doi: 10.1016/j.neuroscience.2011.11.017

Devue, C., Collette, F., Balteau, E., Degueldre, C., Luxen, A., Maquet, P., et al. (2007). Here I am: the cortical correlates of visual self-recognition. Brain Res. 1143, 169-182. doi: 10.1016/j.brainres.2007.01.055

Diamond, L. M., and Dickenson, J. A. (2012). The neuroimaging of love and desire: review and future directions. Clin. Neuropsychiatry 9, 39-46.

Di Martino, A., Scheres, A., Margulies, D. S., Kelly, A. M. C., Uddin, L. Q., Shehzad, Z., et al. (2008). Functional connectivity of human striatum: a resting state FMRI study. Cereb. Cortex 18, 2735-2747. doi: 10.1093/cercor/bhn041

Farrer, C., and Frith, C. D. (2002). Experiencing oneself vs another person as being the cause of an action: the neural correlates of the experience of agency. Neuroimage 15, 596-603. doi: 10.1006/nimg.2001.1009

Fisher, H. E. (1998). Lust, attraction, and attachment in mammalian reproduction. Hum. Nat. 9, 23-52. doi: 10.1007/s12110-998-1010-5

Fisher, H. E., Aron, A., and Brown, L. L. (2006). Romantic love: a mammalian brain system for mate choice. Philos. Trans. R. Soc. B Biol. Sci. 361, 2173-2186. doi: 10.1098/rstb.2006.1938

Fisher, H. E., Brown, L. L., Aron, A., Strong, G., and Mashek, D. (2010). Reward, addiction, and emotion regulation systems associated with rejection in love. J. Neurophysiol. 104, 51-60. doi: 10.1152/jn.00784.2009

Fox, M. D., and Raichle, M. E. (2007). Spontaneous fluctuations in brain activity observed with functional magnetic resonance imaging. Nat. Rev. Neurosci. 8, 700-711. doi: 10.1038/nrn2201

Fox, M. D., Snyder, A. Z., Vincent, J. L., Corbetta, M., Van Essen, D. C., and Raichle, M. E. (2005). The human brain is intrinsically organized into dynamic, anticorrelated functional networks. Proc. Natl. Acad. Sci. U.S.A. 102, 9673-9678. doi: 10.1073/pnas.0504136102

Friston, K. J., Frith, C. D., Liddle, P. F., and Frackowiak, R. S. J. (1993). Functional connectivity: the principal-component analysis of large (PET) data sets. J. Cereb. Blood Flow Metab. 13, 5-14. doi: 10.1038/jcbfm.1993.4

Frith, C. D., and Frith, U. (1999). Interacting minds-a biological basis. Science 286, 1692-1695. doi: 10.1126/science.286.5445.1692

Gallagher, H. L., and Frith, C. D. (2003). Functional imaging of 'theory of mind'. Trends Cogn. Sci. (Regul. Ed.) 7, 77-83. doi: 10.1016/S1364-6613(02)00025-6

Gonzaga, G. C., Turner, R. A., Keltner, D., Campos, B., and Altemus, M. (2006). Romantic love and sexual desire in close relationships. Emotion 6, 163-179. doi: 10.1037/1528-3542.6.2.163

Greene, J., and Haidt, J. (2002). How (and where) does moral judgment work? Trends Cogn. Sci. 6, 517-523. doi: 10.1016/S1364-6613(02)02011-9

Greicius, M. D., Flores, B. H., Menon, V., Glover, G. H., Solvason, H. B., Kenna, H., et al. (2007). Resting-state functional connectivity in major depression: abnormally increased contributions from subgenual cingulate cortex and thalamus. Biol. Psychiatry 62, 429-437. doi: 10.1016/j.biopsych.2006.09.020

Gusnard, D. A., Akbudak, E., Shulman, G. L., and Raichle, M. E. (2001). Medial prefrontal cortex and self-referential mental activity: relation to a default mode of brain function. Proc. Natl. Acad. Sci. U.S.A. 98, 4259-4264. doi: 10.1073/pnas.071043098

Hao, X., Wang, K., Li, W., Yang, W., Wei, D., Qiu, J., et al. (2013). Individual differences in brain structure and resting brain function underlie cognitive styles: evidence from the embedded figures test. PLOS ONE 8:e78089. doi: 10.1371/journal.pone.0078089

Hatfield, E., and Rapson, R. L. (1993). Historical and cross-cultural perspectives on passionate love and sexual desire. Annu. Rev. Sex Res. 4, 67-97. 
Hatfield, E., and Sprecher, S. (1986). Measuring passionate love in intimate relationships. J. Adolesc. 9, 383-410. doi: 10.1016/S0140-1971(86)8 0043-4

Hazan, C., and Shaver, P. (1987). Romantic love conceptualized as an attachment process. J. Pers. Soc. Psychol. 52, 511-524. doi: 10.1037/0022-3514. 52.3.511

Jankowiak, W. R., and Fischer, E. F. (1992). A cross-cultural perspective on romantic love. Ethnology 31, 149-155. doi: 10.2307/3773618

Kelly, A. M. C., Uddin, L. Q., Biswal, B. B., Castellanos, F. X., and Milham, M. P. (2008). Competition between functional brain networks mediates behavioral variability. Neuroimage 39, 527-537. doi: 10.1016/j.neuroimage.2007.08.008

Kendrick, K. (2000). Oxytocin, motherhood and bonding. Exp. Physiol. 85, 111S124S. doi: 10.1111/j.1469-445X.2000.tb00014.x

Knutson, B., Taylor, J., Kaufman, M., Peterson, R., and Glover, G. (2005). Distributed neural representation of expected value. J. Neurosci. 25, 4806-4812. doi: 10.1523/JNEUROSCI.0642-05.2005

Knutson, B., and Wimmer, G. E. (2007). Splitting the difference. Ann. N. Y. Acad. Sci. 1104, 54-69. doi: 10.1196/annals.1390.020

Koshino, H., Kana, R. K., Keller, T. A., Cherkassky, V. L., Minshew, N. J., and Just, M. A. (2008). fMRI investigation of working memory for faces in autism: visual coding and underconnectivity with frontal areas. Cereb. Cortex 18, 289-300. doi: 10.1093/cercor/bhm054

Lane, R. D., Fink, G. R., Chau, P. M.-L., and Dolan, R. J. (1997). Neural activation during selective attention to subjective emotional responses. Neuroreport 8, 3969 3972. doi: 10.1097/00001756-199712220-00024

Lane, R. D., Reiman, E. M., Axelrod, B., Yun, L.-S., Holmes, A., and Schwartz, G. E. (1998). Neural correlates of levels of emotional awareness: evidence of an interaction between emotion and attention in the anterior cingulate cortex. J. Cogn. Neurosci. 10, 525-535. doi: 10.1162/0898929985 62924

Lauwereyns, J. (2006). Voluntary control of unavoidable action. Trends Cogn. Sci. (Regul. Ed.) 10, 47-49. doi: 10.1016/j.tics.2005.11.012

Lee, M. H., Smyser, C. D., and Shimony, J. S. (2013). Resting-state fMRI: a review of methods and clinical applications. Am. J. Neuroradiol. 34, 1866-1872. doi: 10.3174/ajnr.A3263

Liu, C., Liu, Y., Li, W., Wang, D., Jiang, T., Zhang, Y. C., et al. (2011). Increased regional homogeneity of blood oxygen level-dependent signals in occipital cortex of early blind individuals. Neuroreport 22, 190-194. doi: 10.1097/WNR.0b013e3283447c09

Liu, H., Liu, Z., Liang, M., Hao, Y., Tan, L., Kuang, F., et al. (2006). Decreased regional homogeneity in schizophrenia: a resting state functional magnetic resonance imaging study. Neuroreport 17, 19-22. doi: 10.1097/01.wnr.0000195666.2 2714.35

Liu, J., Gao, X. P., Osunde, I., Li, X., Zhou, S. K., Zheng, H. R., et al. (2010). Increased regional homogeneity in internet addiction disorder a resting state functional magnetic resonance imaging study. Chin. Med. J. (Engl) 123, 1904-1908.

Liu, Y., and Wang, Z. X. (2003). Nucleus accumbens oxytocin and dopamine interact to regulate pair bond formation in female prairie voles. Neuroscience 121, 537544. doi: 10.1016/S0306-4522(03)00555-4

Lynall, M.-E., Bassett, D. S., Kerwin, R., McKenna, P. J., Kitzbichler, M., Muller, U., et al. (2010). Functional connectivity and brain networks in schizophrenia. J. Neurosci. 30, 9477-9487. doi: 10.1523/JNEUROSCI.0333-1 0.2010

Maddock, R. J. (1999). The retrosplenial cortex and emotion: new insights from functional neuroimaging of the human brain. Trends Neurosci. 22, 310-316. doi: 10.1016/S0166-2236(98)01374-5

Mogenson, G. J., Jones, D. L., and Yim, C. Y. (1980). From motivation to action: functional interface between the limbic system and the motor system. Prog. Neurobiol. 14,69-97. doi: 10.1016/0301-0082(80)90018-0

Moll, J., de Oliveira-Souza, R., Bramati, I. E., and Grafman, J. (2002). Functional networks in emotional moral and nonmoral social judgments. Neuroimage 16, 696-703. doi: 10.1006/nimg.2002.1118

Ortigue, S., Bianchi-Demicheli, F., Hamilton, A. F. C., and Grafton, S. T. (2007) The neural basis of love as a subliminal prime: an event-related functional magnetic resonance imaging study. J. Cogn. Neurosci. 19, 1218-1230. doi: 10.1162/jocn.2007.19.7.1218

Ortigue, S., Bianchi-Demicheli, F., Patel, N., Frum, C., and Lewis, J. W. (2010). Neuroimaging of love: fMRI meta-analysis evidence toward new perspectives in sexual medicine. J. Sex. Med. 7, 3541-3552. doi: 10.1111/j.1743-6109.2010. 01999.x

Paakki, J.-J., Rahko, J., Long, X., Moilanen, I., Tervonen, O., Nikkinen, J., et al. (2010). Alterations in regional homogeneity of resting-state brain activity in autism spectrum disorders. Brain Res. 1321, 169-179. doi: 10.1016/j.brainres.2009. 12.081

Paulus, M. P., and Stein, M. B. (2006). An insular view of anxiety. Biol. Psychiatry 60, 383-387. doi: 10.1016/j.biopsych.2006.03.042

Peele, S., and Brodsky, A. (1975). Love and Addiction. Oxford: Taplinger press.

Preuschoff, K., Quartz, S. R., and Bossaerts, P. (2008). Human insula activation reflects risk prediction errors as well as risk. J. Neurosci. 28, 2745-2752. doi: 10.1523/JNEUROSCI.4286-07.2008

Raichle, M. E., MacLeod, A. M., Snyder, A. Z., Powers, W. J., Gusnard, D. A., and Shulman, G. L. (2001). A default mode of brain function. Proc. Natl. Acad. Sci. U.S.A. 98, 676-682. doi: 10.1073/pnas.98.2.676

Reynolds, S. M., and Zahm, D. S. (2005). Specificity in the projections of prefrontal and insular cortex to ventral striatopallidum and the extended amygdala. J. Neurosci. 25, 11757-11767. doi: 10.1523/JNEUROSCI.343205.2005

Rilling, J. K., DeMarco, A. C., Hackett, P. D., Thompson, R., Ditzen, B., Patel, R., et al. (2012). Effects of intranasal oxytocin and vasopressin on cooperative behavior and associated brain activity in men. Psychoneuroendocrinology 37, 447-461. doi: 10.1016/j.psyneuen.2011.07.013

Sabatinelli, D., Bradley, M. M., Lang, P. J., Costa, V. D., and Versace, F. (2007). Pleasure rather than salience activates human nucleus accumbens and medial prefrontal cortex. J. Neurophysiol. 98, 1374-1379. doi: 10.1152/jn.002 30.2007

Seymour, B., O’Doherty, J. P., Dayan, P., Koltzenburg, M., Jones, A. K., Dolan, R. J., et al. (2004). Temporal difference models describe higher-order learning in humans. Nature 429, 664-667. doi: 10.1038/nature02581

Shukla, D. K., Keehn, B., and Müller, R. A. (2010). Regional homogeneity of fMRI time series in autism spectrum disorders. Neurosci. Lett. 476, 46-51. doi: 10.1016/j.neulet.2010.03.080

Song, X. W., Dong, Z. Y., Long, X. Y., Li, S. F., Zuo, X. N., Zhu, C. Z., et al. (2010). REST: a toolkit for resting-state functional magnetic resonance imaging data processing. PLOS ONE 6:e25031. doi: 10.1371/journal.pone.00 25031

Sternberg, R. J. (1986). A triangular theory of love. Psychol. Rev. 93, 119-135. doi: 10.1037/0033-295X.93.2.119

Stoffers, D., Bosboom, J. L. W., Deijen, J. B., Wolters, E. C., Stam, C. J., and Berendse, H. W. (2008). Increased cortico-cortical functional connectivity in early-stage Parkinson's disease: an MEG study. Neuroimage 41, 212-222. doi: 10.1016/j.neuroimage.2008.02.027

Sue Carter, C., Courtney, D. A., and Getz, L. L. (1995). Physiological substrates of mammalian monogamy: the prairie vole model. Neurosci. Biobehav. Rev. 19, 303-314. doi: 10.1016/0149-7634(94)00070-H

Tarlaci, S. (2012). The brain in love: has neuroscience stolen the secret of love? NeuroQuantology 10, 744-753. doi: 10.14704/nq.2012.10. 4.581

Tsakiris, M., Hesse, M. D., Boy, C., Haggard, P., and Fink, G. R. (2007). Neural signatures of body ownership: a sensory network for bodily self-consciousness. Cereb. Cortex 17, 2235-2244. doi: 10.1093/cercor/ bhl131

Van Den Heuvel, M. P., and Hulshoff Pol, H. E. (2010). Exploring the brain network: a review on resting-state fMRI functional connectivity. Eur. Neuropsychopharmacol. 20, 519-534. doi: 10.1016/j.euroneuro.2010.03.008

Van Rooy, D. L., Viswesvaran, C., and Pluta, P. (2005). An evaluation of construct validity: what is this thing called emotional intelligence? Hum. Perform. 18, 445462. doi: 10.1207/s15327043hup1804_9

Waldherr, M., and Neumann, I. D. (2007). Centrally released oxytocin mediates mating-induced anxiolysis in male rats. Proc. Natl. Acad. Sci. U.S.A. 104, 1668116684. doi: 10.1073/pnas.0705860104

Wang, Z., Hulihan, T. J., and Insel, T. R. (1997). Sexual and social experience is associated with different patterns of behavior and neural activation in male prairie voles. Brain Res. 767, 321-332. doi: 10.1016/S0006-8993(97) 00617-3

Winslow, J. T., Hastings, N., Carter, C. S., Harbaugh, C. R., and Insel, T. R. (1993). A role for central vasopressin in pair bonding in monogamous prairie voles. Nature 365, 545-548. doi: 10.1038/365545a0 
Winston, J. S., Strange, B. A., O’Doherty, J., and Dolan, R. J. (2002). Automatic and intentional brain responses during evaluation of trustworthiness of faces. Nat. Neurosci. 5, 277-283. doi: 10.1038/nn816

Wu, T., Long, X., Zang, Y., Wang, L., Hallett, M., Li, K., et al. (2009). Regional homogeneity changes in patients with Parkinson's disease. Hum. Brain Mapp. 30, 1502-1510. doi: 10.1002/hbm.20622

Xu, X., Aron, A., Brown, L., Cao, G., Feng, T., and Weng, X. (2011). Reward and motivation systems: a brain mapping study of early-stage intense romantic love in Chinese participants. Hum. Brain Mapp. 32, 249-257. doi: 10.1002/hbm. 21017

Yao, Z., Wang, L., Lu, Q., Liu, H., and Teng, G. (2009). Regional homogeneity in depression and its relationship with separate depressive symptom clusters: a resting-state fMRI study. J. Affect. Disord. 115, 430-438. doi: 10.1016/j.jad.2008.10.013

Yin, J., Zhang, J. X., Xie, J., Zou, Z., and Huang, X. (2013). Gender differences in perception of romance in Chinese college students. PLOS ONE 8:e76294. doi: 10.1371/journal.pone.0076294

Zang, Y., Jiang, T., Lu, Y., He, Y., and Tian, L. (2004). Regional homogeneity approach to fMRI data analysis. Neuroimage 22, 394-400. doi: 10.1016/j.neuroimage.2003.12.030

Zeki, S. (2007). The neurobiology of love. FEBS Lett. 581, 2575-2579. doi: 10.1016/j.febslet.2007.03.094
Zhang, Z., Liu, Y., Jiang, T., Zhou, B., An, N., Dai, H., et al. (2012). Altered spontaneous activity in Alzheimer's disease and mild cognitive impairment revealed by regional homogeneity. Neuroimage 59, 1429-1440. doi: 10.1016/j.neuroimage.2011.08.049

Conflict of Interest Statement: The authors declare that the research was conducted in the absence of any commercial or financial relationships that could be construed as a potential conflict of interest.

Received: 25 September 2014; accepted: 28 January 2015; published online: 13 February 2015.

Citation: Song H, Zou Z, Kou J, Liu Y, Yang L, Zilverstand A, d'Oleire Uquillas F and Zhang $X$ (2015) Love-related changes in the brain: a resting-state functional magnetic resonance imaging study. Front. Hum. Neurosci. 9:71. doi: 10.3389/fnhum.2015.00071 This article was submitted to the journal Frontiers in Human Neuroscience. Copyright ( 12015 Song, Zou, Kou, Liu, Yang, Zilverstand, d'Oleire Uquillas and Zhang. This is an open-access article distributed under the terms of the Creative Commons Attribution License (CC BY). The use, distribution or reproduction in other forums is permitted, provided the original author(s) or licensor are credited and that the original publication in this journal is cited, in accordance with accepted academic practice. No use, distribution or reproduction is permitted which does not comply with these terms. 